\title{
Chemopreventive Action by Ethanol-extracted Brazilian Green Propolis on Post-initiation Phase of Inflammation-associated Rat Colon Tumorigenesis
}

\author{
KENICHIRO DOI, MASAKI FUJIOKA, YUI SOKUZA, MARIKO OHNISHI, MIN GI, \\ MASANORI TAKESHITA, KENJI KUMADA, ANNA KAKEHASHI and HIDEKI WANIBUCHI \\ Department of Molecular Pathology, Osaka City University Graduate School of Medicine, Osaka, Japan
}

\begin{abstract}
Background/Aim: Propolis has since long been utilized in numerous folk medicines with a variety of medicinal properties. In this study, the effects of ethanol-extracted (EEP) and water-extracted (WEP) Brazilian green propolis on the post-initiation phase of inflammation-associated rat colon tumorigenesis were directly compared. Materials and Methods: Male F344 rats at 6 weeks of age were subcutaneously injected with 1,2-dimethylhydrazine (DMH) at $40 \mathrm{mg} / \mathrm{kg}$ body weight twice during the first week, followed by $1 \%$ dextran sodium sulfate (DSS) in drinking water for one week. After a 1-week no-treatment period, animals were administered either basal Oriental MF powdered diet, or 1\% EEP or $1 \%$ WEP in the basal diet until week 32. Results: Post-initiation treatment with EEP significantly reduced the multiplicity of colorectal carcinomas compared to the control $(0.40 \pm 0.13 /$ rat vs. $2.29 \pm 0.84 /$ rat, respectively, $p<0.05)$, and EEP also reduced the tumor volume. Immunohistochemically, expression of inflammation-associated proteins inducible nitric oxide synthase, tumor necrotic factor alpha, nuclear factor kappa $B$ and glutathione peroxidase-2 were significantly diminished in colorectal tumors from EEP-treated rats. Conclusion: Suppression of inflammation and oxidative stress, which had been triggered by DMH and promoted by DSS, was a primary mechanism by which EEP suppressed carcinogenesis.
\end{abstract}

Colorectal cancer (CRC) has become a major public health concern worldwide. In the United States 134,490 new cases

This article is freely accessible online.

Correspondence to: Hideki Wanibuchi, MD, Ph.D., Department of Molecular Pathology, Osaka City University Graduate School of Medicine, 1-4-3 Asahi-machi, Abeno-ku, Osaka, 545-8585 Japan. Tel: +81 666453737, Fax: +81 666463093, e-mail: wani@med.osaka-cu.ac.jp

Key Words: Ethanol-extracted propolis, rat, colon cancer, dimethylhydrazine, dextran sodium sulfate, inflammation, oxidative stress. and 49,190 deaths were estimated to have occured in 2016 (1), and in Japan it is the leading cause of cancer mortality in women (2). Much is known about the etiologies of CRC, and two critical factors in CRC carcinogenesis are oxidative stress, which is regulated by balancing the production and removal of reactive oxygen and nitrogen species, and inflammation (3-5). These two factors can participate in feedback loops in which carcinogenic steps from initiation to promotion/ progression are repeated over and over again, augmenting the process of carcinogenesis.

Colitis-associated CRC, where crosstalk between chronic inflammation and oxidative stress are likely to be involved in the carcinogenic process (6), has been attracting attention. Regular use of aspirin was shown to reduce the risk of CRC overexpressing cyclooxygenase-2 (COX2) (7). Moreover, aspirin and $\mathrm{COX} 2$ inhibitors significantly improved of patients with CRC (8). Therefore, the concept of chemoprevention to reduce the risk of patients with colitis developing CRC and to improve patient long-term outcome is gaining acceptance. Thus, the current idea of disrupting the feedback loop between oxidative stress and inflammation to counteract colon cancer should be further investigated. In order to investigate the underlying mechanisms of action of environmental chemicals, rodent models have been extensively developed (9). To mimic human CRC, addition of dextran sodium sulfate (DSS) is used to cause inflammation after injection with appropriate carcinogenic initiators, such as dimethylhydrazine $(\mathrm{DMH})(10,11)$ and its bioactive metabolite, azoxymethane (AOM) (12).

Propolis is a naturally-occurring resinous mixture that honey bees collect from tree buds, sap, and other botanical sources. Due to its antiseptic and antimicrobial properties, propolis has long been utilized in folk medicine $(13,14)$. Because it is a highly complex substance, the chemical composition and biological properties of propolis obtained from different regions, such as that produced in India, Thailand, Poland, China and other countries, can be very different (15-19). Importantly, different extraction processes can also yield different bioactive ingredients $(20,21)$. 
Because of the diversity of the products that are obtained from propolis, a variety of effects have been reported (19). Of particular interest to this study are the potential anti-oxidant, anti-inflammatory, and anti-carcinogenic activities of propolis extracts. The anti-oxidative potential of ethanolic extracts of Brazilian green and red propolis seem to be higher than that of Brazilian brown propolis (21). Water (WEP) and ethanolic (EEP) extracts of Brazilian green propolis possess anti-oxidant activity (22), and an aqueous extraction of Brazilian green propolis exhibited anti-inflammatory effects in vivo using mouse models of acute and chronic inflammation (23). A major constituent contained in Brazilian green propolis is artepillin $\mathrm{C}$ (3,5-diprenyl-4-hydroxicinnamic acid), which was found to exert anti-oxidative activity in HepG2 cells in vitro (24) and potent anti-inflammatory effects on lipopolysaccharide plus interferon gamma-activated macrophages in a dose-dependent manner in vitro (25). Although some studies have indicated that propolis has tumor-promoting potential via the non-genotoxic mechanisms $(26,27)$, other studies report that propolis and its chemical constituents are anti-carcinogenic $(28,29)$.

In vivo, both WEP and EEP significantly inhibited AOMinduced formation of aberrant crypt foci (ACF) in rats when administered during the initiation phase of colon carcinogenesis (30), but post-initiation administration of propolis has been reported not to have a significant effect on ACF formation (31, 32). However, due to the complexity of propolis and its extracts, the effects of post-initiation administration of propolis remain uncertain. Post-initiation inhibition of inflammation is of particular interest to patients with inflammatory bowel disease (IBD) because of their high risk of developing colitisassociated CRC. In this study we, therefore, planned to directly compare EEP and WEP treatment during the post-initiation phase of inflammation-associated CRC using an established rat model. In particular, we aimed to analyze probable mechanisms of action by which EEP and WEP might exert their anticarcinogenic activity. We believe that our present study will provide valuable data for prevention of inflammationassociated CRC in humans.

\section{Materials and Methods}

Chemicals and diet. DMH was purchased from Tokyo Chemical Industry Co., Ltd. (Tokyo, Japan). DSS (molecular weight=36,000$50,000)$ was from Wako Pure Chemical Industries Ltd. (Osaka, Japan). Ethanolic extracts and water extracts of Brazilian green propolis were kindly supplied by API Co., Ltd. (Gifu, Japan). In this study, all experimental diets contained $1.5 \%(\mathrm{w} / \mathrm{w})$ dextrin in the basal formula of MF powdered diet (Oriental Yeast Co., Ltd., Tokyo, Japan).

Animal treatment. The protocol of the animal experiment was approvedby the Animal Care and Use Committee of the Osaka City University Graduate School of Medicine (no. 08084) and all experiments were conducted in accordance with their guidelines. A total of 127, 5-week-old male Fisher 344 rats were purchased from Charles River Laboratories Japan Inc. (Atsugi, Japan) and maintained in an animal facility with a temperature of $24 \pm 2^{\circ} \mathrm{C}$, a humidity of $60 \pm 10 \%$ and a 12 -h light/dark cycle. Rats were housed in plastic cages (3/cage) with free access to tap water and basal Oriental MF powdered diet containing $1.5 \%(\mathrm{w} / \mathrm{w})$ dextrin. After a 1 -week acclimation period, they were used for the study. Rats were divided into eight body weight-matched groups as follows: group 1 had 32 rats, groups 2 and 3 had 35 rats each, and groups 4-8 had five rats each, as shown in Figure 1. Animals in groups 1-3 were subcutaneously (s.c.) injected twice with DMH dissolved in physiological saline $(0.9 \%)$ at $40 \mathrm{mg} / \mathrm{kg}$ body weight (b.w.) during the initial week of the experimental period, followed by administration of $1 \%$ DSS in the drinking water for one week. Animals in groups 4-8 were s.c. injected with vehicle saline (1 $\mathrm{ml}$ each); rats in groups 4 and 5 were administered 1\% DSS in the drinking water during the second week and those in groups 6-8 did not have DSS in their drinking water. After a 1-week no-treatment period (third week), rats in groups 2, 4 and 6 were fed basal powdered diet containing $1 \% \mathrm{EEP}(\mathrm{w} / \mathrm{w})$; rats in groups 3, 5 and 7 were fed basal powdered diet containing $1 \% \mathrm{WEP}(\mathrm{w} / \mathrm{w})$ throughout the remainder of the experimental period. Groups 1 and 8 were fed basal diet without EEP or WEP. At week 12, 15 rats each from groups 1-3 were sacrificed under diethyl-ether anesthesia (Nacalai tesque, Kyoto, Japan) and the liver, kidneys and colorectum were excised for histopathological examination. After 32 weeks, all animals were sacrificed under diethyl-ether anesthesia and the liver, kidneys and colorectum were excised for histopathological examination.

Organ and tissue processing. The liver and kidneys were weighed and fixed in $10 \%$ phosphate-buffered formalin solution and 4- $\mu$ m-thick sections were routinely prepared for hematoxylin and eosin (H\&E) staining. The colons were prepared as previously described (33). In brief, normal saline $(0.9 \%)$ was injected into the lumen of the colons and kept for a few minutes for trimming of external connective and adipose tissues. Colons were cut open longitudinally, washed with saline, extended between two filter papers and fixed in $10 \%$ formalin solution for more than $24 \mathrm{~h}$ at $4^{\circ} \mathrm{C}$. At week 12, ACFs were counted as described below. At week 32, mucosal surfaces of the fixed colons were carefully inspected and any visible tumors were recorded. The three dimensions (length, width, depth) of all grossly evident neoplasms were measured for calculation of each tumor volume using the formula: tumor volume $\left(\mathrm{mm}^{3}\right)=$ length $\times$ width $\times$ depth $\times \pi / 6(34)$. All tumors were prepared for H\&E staining and histopathologically diagnosed as tubular adenoma, adenocarcinoma, and signet-ring cell carcinoma with reference to an experimental rat model (35). At least two transverse sections from the proximal, middle, and distal regions of each colorectum were prepared for H\&E staining.

Examination of ACF. Fifteen rats each from groups 1-3 were examined for $\mathrm{ACF}$ at week 12. After fixation, the colons were dipped in $0.2 \%$ methylene blue in distilled water for 1-2 min, briefly washed with distilled water and placed on microscope slides with the mucosal surface uppermost. According to the criteria of Bird (36), ACF were detected at a magnification of $\times 40$ under a light microscope (Olympus BX41; Olympus Optical Co., Ltd., Tokyo, Japan), and the number of $\mathrm{ACF}$ in each colonic segment were counted and the number of ACs in each ACF were also evaluated (classified as $1 \mathrm{AC}, 2 \mathrm{ACs}, 3 \mathrm{ACs}$ and $\geq 4 \mathrm{ACs}$ ). After counting and evaluating $\mathrm{ACF}$, tumors were prepared for $\mathrm{H} \& \mathrm{E}$ staining and histopathological diagnosis.

Immunohistochemical (IHC) staining for proliferating cell nuclear antigen (PCNA), adenomatous polyposis coli (APC), $\beta$-catenin, 


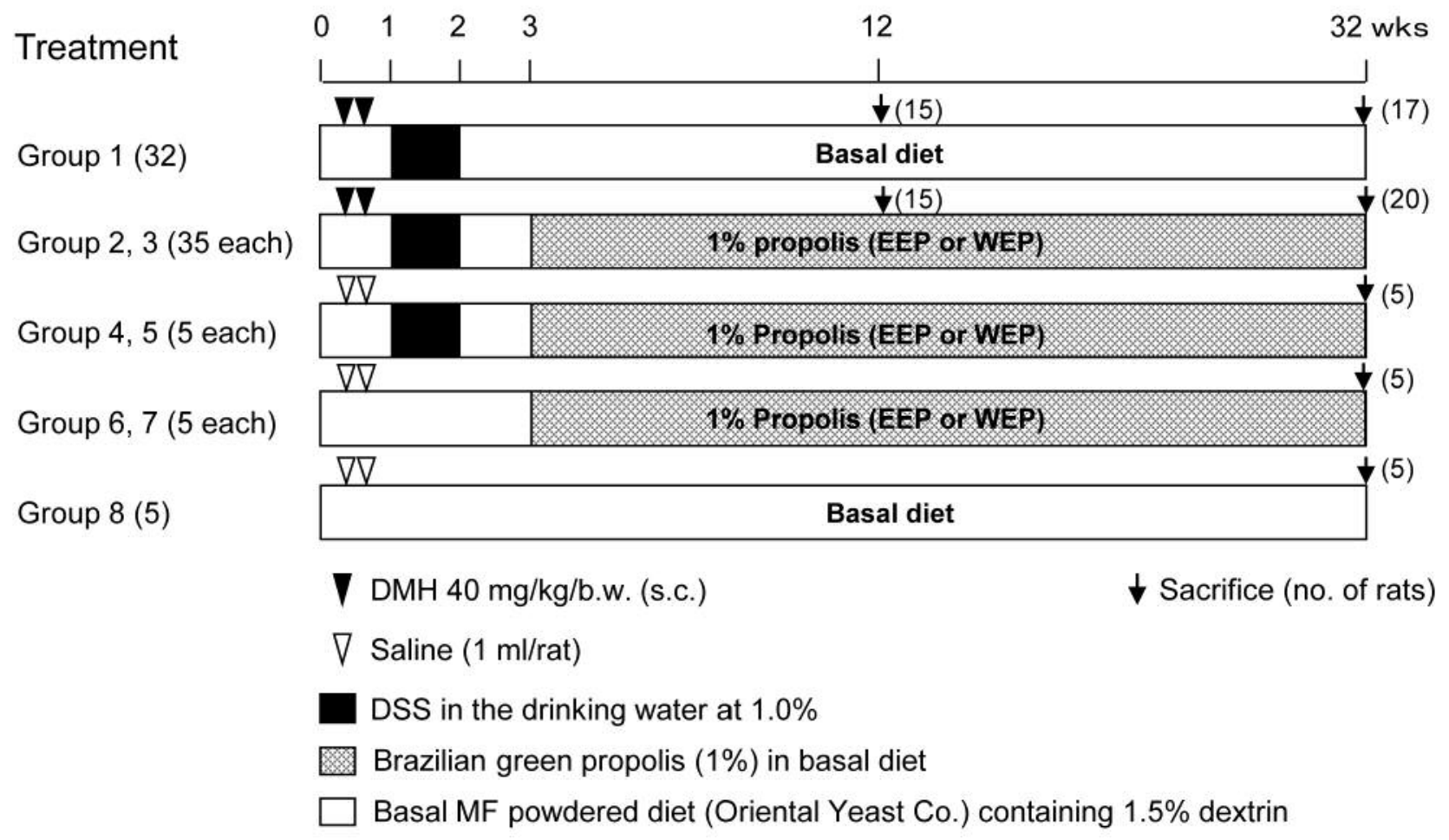

Figure 1. Experimental protocol for inflammation-associated rat colon carcinogenesis. A total of 127, 6-week-old male F344 rats were divided into eight groups. Animals in groups 1-3 were subcutaneously (s.c.) injected twice with 1,2-dimethylhydrazine (DMH) dissolved in physiological saline $(40 \mathrm{mg} / \mathrm{kg}$ body wt.) during the first week. DMH treatment was followed by a 1-week-administration of $1 \%$ dextran sodium sulfate (DSS) in the drinking water during the second week. Rats in group 4-8 were s.c. injected with $1 \mathrm{ml}$ of saline and group 4 and 5 rats were administered 1\% DSS during the second week. All animals were maintained without any chemical treatment during the third week. At the beginning of the fourth week, group 2, 4 and 6 rats were fed 1\% ethanol-extracted propolis (EEP); group 3, 5 and 7 rats were fed 1\% water-extracted propolis (WEP); and group 1 and 8 rats were fed basal MF powdered diet containing 1.5\% dextrin. Administration of EEP or WEP was continued until the end of the 32nd-week. At week 12, 15 rats each from groups 1-3 were sacrificed for analysis of aberrant crypt foci $(A C F)$ and all remaining animals were sacrificed at the end of week 32.

inducible nitric oxide synthase (iNOS), COX2, nuclear factor kappa $B(N F-\kappa B)$, tumor necrosis factor alpha $(T N F \alpha)$ and glutathione peroxidase-2 (GPX2) in colonic tumors at week 32. Immunohistochemical staining for PCNA, APC, $\beta$-catenin, iNOS, $\mathrm{COX} 2, \mathrm{NF}-\mathrm{KB}, \mathrm{TNF} \alpha$ and GPX2 were conducted using the avidinbiotin-peroxidase complex (ABC) method (Vectastain ABC kit; Vector Laboratories, Burlingame, CA, USA). Four-micrometer-thick serial sections were sequentially treated with $10 \mathrm{mM}$ citrate buffer ( $\mathrm{pH}$ 6.0) in a microwave at $98^{\circ} \mathrm{C}$ for $25 \mathrm{~min}, 3 \% \mathrm{H}_{2} \mathrm{O}_{2}$ for $5 \mathrm{~min}$, washed 3 times (5 min each) with PBS ( $\mathrm{pH} 7.2$ ), incubated with normal serum (horse or goat) for $15 \mathrm{~min}$ for blocking, followed by overnight incubation with primary antibodies at $4^{\circ} \mathrm{C}$, as follows: mouse monoclonal anti-PCNA (diluted 1:100; DAKO Japan Co., Ltd., Kyoto, Japan); mouse monoclonal anti-APC (diluted 1:1,000; BD Biosciences, San Jose, CA, USA); mouse monoclonal anti- $\beta$-catenin diluted 1:100 (BD Biosciences), mouse monoclonal anti-iNOS diluted 1:200 (BD Biosciences); mouse monoclonal anti-COX2 diluted 1:500 (BD Biosciences); mouse monoclonal anti-NF-KB p65 (sc-8008, diluted 1:100; Santa Cruz Biotechnology, Dallas, TX, USA); rabbit polyclonal anti-TNF $\alpha$ (ab6671, diluted 1:100; Abcam, Cambridge, MA, USA); goat polyclonal anti-GPX2 (NB100-1888, diluted 1:100; Novus Biologicals, Littleton, CO, USA). The following day, slides were incubated with appropriate biotin-labeled secondary IgG for 30 min, $\mathrm{ABC}$ reagent for 30 min, visualized with 3,3'-diamonobenzidine tetrahydrochloride (DAB) (Wako Pure Chemical Industries Ltd.), and counterstained with hematoxylin.

IHC evaluation of colonic tumors at week 32 . All IHC analysis was carried out under a light microscope at $\times 400$ magnification. For assessment of APC and $\beta$-catenin, a total of 58, 14 and 37 tumors were randomly selected from group 1,2 and 3 rats, respectively (rats in groups 4-8 did not develop any tumors). Tumors (adenomas and adenocarcinomas) with positive APC or $\beta$-catenin staining of $\geq 10 \%$ epithelial cell nuclei were defined as IHC-positive. For iNOS and COX2, each tumor was divided into epithelial and stromal areas (stroma contains fibroblasts, lymphocytes, plasma cells, endothelial cells and others), and the scoring was carried out in accordance with the following criterion: - , none; \pm , partially stained; + , mild to moderately stained in $<50 \%$ cells; ++ , mild to moderately stained in $\geq 50 \%$ cells, which could include some strongly stained cells; +++, majority of the cells were strongly stained.

For assessment of NF-kB, TNF $\alpha$ and GPX2, a total of 71, 19 and either 41 or 44 tumors (see Table VI) from group 1-3 rats, respectively, were evaluated. Most of the epithelial cells exhibited at least faint positive staining for these three proteins. Therefore, the scoring for tumor epithelium was as follows: - , none; \pm , faintly stained or partially 
Table I. Average intake of water and diet, and estimated propolis intake.

\begin{tabular}{|c|c|c|c|c|c|c|}
\hline \multirow[t]{2}{*}{ Group } & \multirow[t]{2}{*}{ Treatment } & \multicolumn{2}{|c|}{ Average intake ( $\mathrm{g} / \mathrm{rat} /$ day) } & \multicolumn{2}{|c|}{ Estimated propolis intake in rats } & \multirow{2}{*}{$\begin{array}{l}\text { Equivalent propolis } \\
\text { intake in human } \\
(\mathrm{g} / \text { person/day })^{\mathrm{a}}\end{array}$} \\
\hline & & Water & Diet & (g/kg/day) & Total duration $(\mathrm{g} / \mathrm{kg})$ & \\
\hline 1 & $\mathrm{DMH}+\mathrm{DSS} \rightarrow$ Basal & 17.8 & 13.5 & 0 & 0 & 0 \\
\hline 2 & $\mathrm{DMH}+\mathrm{DSS} \rightarrow \mathrm{EEP}$ & 18.9 & 13.6 & 0.43 & 89.8 & 25.6 \\
\hline 3 & $\mathrm{DMH}+\mathrm{DSS} \rightarrow \mathrm{WEP}$ & 17.7 & 13.6 & 0.42 & 89.2 & 25.5 \\
\hline 4 & $\mathrm{DSS} \rightarrow \mathrm{EEP}$ & 18.2 & 13.7 & 0.43 & 89.5 & 25.6 \\
\hline 5 & $\mathrm{DSS} \rightarrow \mathrm{WEP}$ & 16.9 & 13.7 & 0.43 & 91.2 & 26.1 \\
\hline 6 & EEP & 18.9 & 14.3 & 0.44 & 93.3 & 26.7 \\
\hline 7 & WEP & 18.4 & 14.2 & 0.44 & 91.7 & 26.2 \\
\hline 8 & Basal & 18.1 & 14.8 & 0 & 0 & 0 \\
\hline
\end{tabular}

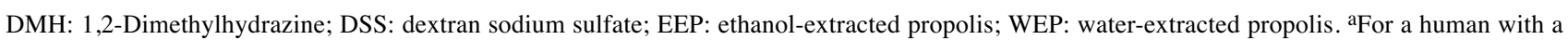
body weight of $60 \mathrm{~kg}$.

Table II. Final body and organ weights at weeks 12 and 32 . Values are the mean $\pm S D$.

\begin{tabular}{|c|c|c|c|c|c|}
\hline \multirow[t]{2}{*}{ Group } & \multirow[t]{2}{*}{ Treatment } & \multirow[t]{2}{*}{ No. of rats } & \multirow[t]{2}{*}{ Final body weight (g) } & \multicolumn{2}{|c|}{ Relative organ weight (g/100g b.w.) } \\
\hline & & & & Liver & Kidneys \\
\hline \multicolumn{6}{|c|}{ Week 12} \\
\hline 1 & $\mathrm{DMH}+\mathrm{DSS}$ & 15 & $317.1 \pm 3.5$ & $2.7 \pm 0.1$ & $0.57 \pm 0.02$ \\
\hline 2 & $\mathrm{DMH}+\mathrm{DSS} \rightarrow \mathrm{EEP}$ & 15 & $316.1 \pm 3.7$ & $2.8 \pm 0.1^{*}$ & $0.59 \pm 0.02 *$ \\
\hline 3 & $\mathrm{DMH}+\mathrm{DSS} \rightarrow \mathrm{WEP}$ & 15 & $312.9 \pm 3.2$ & $2.7 \pm 0.1$ & $0.58 \pm 0.02$ \\
\hline \multicolumn{6}{|c|}{ Week 32} \\
\hline 1 & DMH+DSS & 17 & $369.7 \pm 20.5$ & $2.6 \pm 0.1$ & $0.58 \pm 0.04$ \\
\hline 2 & $\mathrm{DMH}+\mathrm{DSS} \rightarrow \mathrm{EEP}$ & 20 & $368.3 \pm 12.0$ & $2.8 \pm 0.1^{*}$ & $0.58 \pm 0.02$ \\
\hline 3 & $\mathrm{DMH}+\mathrm{DSS} \rightarrow \mathrm{WEP}$ & 20 & $369.4 \pm 24.7$ & $2.6 \pm 0.1$ & $0.57 \pm 0.03$ \\
\hline 4 & $\mathrm{DSS} \rightarrow \mathrm{EEP}$ & 5 & $359.0 \pm 14.7$ & $2.8 \pm 0.1$ & $0.58 \pm 0.03$ \\
\hline 5 & DSS $\rightarrow$ WEP & 5 & $368.3 \pm 14.6$ & $2.6 \pm 0.1$ & $0.56 \pm 0.02$ \\
\hline 6 & EEP & 5 & $368.1 \pm 14.6$ & $2.8 \pm 0.1 * *$ & $0.57 \pm 0.02$ \\
\hline 7 & WEP & 5 & $370.0 \pm 19.4$ & $2.6 \pm 0.1$ & $0.58 \pm 0.01 * *$ \\
\hline 8 & Basal diet & 5 & $388.5 \pm 17.7$ & $2.7 \pm 0.1$ & $0.55 \pm 0.01$ \\
\hline
\end{tabular}

DMH: 1,2-Dimethylhydrazine; DSS: dextran sodium sulfate; EEP: ethanol-extracted propolis; WEP: water-extracted propolis. Significantly different from *group 1 and **group 8 at $p<0.05$.

positive; + , majority of the cells were mildly stained; ++ , majority of the cells were moderately stained; +++, majority of the cells were markedly stained. On the other hand, the positively stained stromal cells were individually countable; therefore the scoring of stromal cells in each tumor was as follows: - , none;,$\pm>0$ and $\leq 5 \%$ cells were positive;,$+>5$ and $\leq 25 \%$ cells were positive;,$++>25$ and $\leq 50 \%$ cells were positive;,$+++>50 \%$ cells were positively stained.

For evaluation of PCNA-positive cells, 10 or more tumors from group 1-3 rats were randomly stained, and $>1,000$ epithelial cells were counted in each tumor. Data are expressed as the percentages of positive cells.

TUNEL staining in colorectal tumors. At week 32, staining for terminal deoxynucleotidyl transferase-mediated deoxyuridine triphosphate nick-end labeling (TUNEL) was performed using an ApopTag ${ }^{\circledR}$ Peroxidase In Situ Apoptosis Detection Kit (CHEMICON ${ }^{\circledR}$
Table III. Colonic aberrant crypt foci (ACF) formation at week 12 . Values are the mean $\pm S D$.

\begin{tabular}{lccc}
\hline & \multicolumn{3}{c}{ Average number of ACF } \\
\cline { 2 - 4 } Group & G1 $(\mathrm{n}=15)$ & $\mathrm{G} 2(\mathrm{n}=15)$ & $\mathrm{G} 3(\mathrm{n}=15)$ \\
Treatment & DMH+DSS & DMH+DSS $\rightarrow$ EEP & DMH+DSS $\rightarrow$ WEP \\
\hline 1 AC & $14.2 \pm 4.8$ & $12.8 \pm 5.4$ & $16.6 \pm 7.6$ \\
2 ACs & $18.0 \pm 8.6$ & $16.3 \pm 8.0$ & $20.3 \pm 7.8$ \\
3 ACs & $17.7 \pm 7.4$ & $16.5 \pm 7.0$ & $19.4 \pm 8.4$ \\
$\geq 4$ ACs & $34.1 \pm 20.4$ & $33.3 \pm 18.9$ & $38.7 \pm 18.1$ \\
Total ACF & $84.0 \pm 34.8$ & $78.9 \pm 34.2$ & $95.0 \pm 34.4$ \\
\hline
\end{tabular}

DMH: 1,2-Dimethylhydrazine; DSS: dextran sodium sulfate; EEP: ethanol-extracted propolis; WEP: water-extracted propolis; AC: aberrant crypt. 
Doi et al: Colon Cancer Chemoprevention by Propolis

Table IV. Incidence (\%) in rats bearing colorectal tumors at week 12 and 32.

\begin{tabular}{|c|c|c|c|c|c|c|c|}
\hline Group & Treatment & No. of rats & Ad & $\mathrm{AC}$ & Sig & Carcinomas $^{\mathrm{a}}$ & Total tumors \\
\hline \multicolumn{8}{|c|}{ Week 12} \\
\hline 1 & DMH+DSS & 15 & $2(13.3 \%)$ & $2(13.3 \%)$ & $2(13.3 \%)$ & $4(26.7 \%)$ & $5(33.3 \%)$ \\
\hline 2 & $\mathrm{DMH}+\mathrm{DSS} \rightarrow \mathrm{EEP}$ & 15 & $3(20.0 \%)$ & $3(20.0 \%)$ & $1(6.7 \%)$ & $4(26.7 \%)$ & $5(33.3 \%)$ \\
\hline 3 & $\mathrm{DMH}+\mathrm{DSS} \rightarrow \mathrm{WEP}$ & 15 & $1(6.7 \%)$ & $2(13.3 \%)$ & 0 & $2(13.3 \%)$ & $2(13.3 \%)$ \\
\hline \multicolumn{8}{|c|}{ Week 32} \\
\hline 1 & DMH+DSS & 17 & $6(35.3 \%)$ & $10(58.8 \%)$ & $2(11.8 \%)$ & $11(64.7 \%)$ & $11(64.7 \%)$ \\
\hline 2 & $\mathrm{DMH}+\mathrm{DSS} \rightarrow \mathrm{EEP}$ & 20 & $7(35 \%)$ & $7(35 \%)$ & 0 & $7(35 \%)$ & $10(50 \%)$ \\
\hline 3 & $\mathrm{DMH}+\mathrm{DSS} \rightarrow \mathrm{WEP}$ & 20 & $8(40 \%)$ & $11(55 \%)$ & 0 & $11(55 \%)$ & $12(60 \%)$ \\
\hline 4 & $\mathrm{DSS} \rightarrow \mathrm{EEP}$ & 5 & 0 & 0 & 0 & 0 & 0 \\
\hline 5 & $\mathrm{DSS} \rightarrow \mathrm{WEP}$ & 5 & 0 & 0 & 0 & 0 & 0 \\
\hline 6 & EEP & 5 & 0 & 0 & 0 & 0 & 0 \\
\hline 7 & WEP & 5 & 0 & 0 & 0 & 0 & 0 \\
\hline 8 & Basal diet & 5 & 0 & 0 & 0 & 0 & 0 \\
\hline
\end{tabular}

DMH: 1,2-Dimethylhydrazine; DSS: dextran sodium sulfate; EEP: ethanol-extracted propolis; WEP: water-extracted propolis; Ad: adenoma; AC:

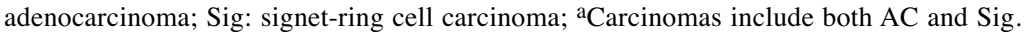

International, Inc., Billerica, MA, USA). Sections were first incubated with $20 \mu \mathrm{g} / \mathrm{ml}$ proteinase $\mathrm{K}$ in PBS for $15 \mathrm{~min}$, then sequentially treated with $3 \% \mathrm{H}_{2} \mathrm{O}_{2}$ for $5 \mathrm{~min}, 75 \mu \mathrm{l}$ of Equilibration buffer for 10 s, $55 \mu \mathrm{l}$ of Working Strength TdT enzyme at $37^{\circ} \mathrm{C}$ for $1 \mathrm{~h}$, Working Strength Stop/Wash Buffer for $10 \mathrm{~min}$ and $65 \mu \mathrm{l}$ of Anti-Digoxigenin Peroxidase Conjugate for $30 \mathrm{~min}$. TUNEL-positive nuclei were visualized with $\mathrm{DAB}$, followed by hematoxylin counterstaining, and $>2000$ epithelial cells were counted in each tumor at a magnification of $\times 400$ ( $n=15,12$ and 13 in groups $1-3$, respectively).

Statistical analysis. Statistical analysis was performed with the aid of GraphPad Prism, Ver.6.0 (GraphPad Software, Inc., La Jolla, CA, USA). Numerical values for each group were routinely subjected to F-test, followed by parametric unpaired $t$-test, and are primarily expressed as mean \pm standard deviation (SD). Tumor multiplicity (number/rat), tumor volume (volume/each tumor), and PCNA and TUNEL data are expressed as mean \pm standard error of mean (SEM). Tumor incidence and IHC scoring data were analyzed by either $\chi^{2}$ or Fisher's exact probability test, according to the minimum number of samples in each setting. For all cases, a value of $p<0.05$ was considered to be statistically significant.

\section{Results}

General condition of the animals. In general, all animals survived until sacrifice. Throughout the experiment, water intake tended to be higher in the 1\% EEP-treated rats (groups 2, 4 and 6), while food consumption did not vary (Table I). Table II summarizes the final body weights and relative liver and kidney weights of animals in all groups. Final body weights did not vary between the groups at either week 12 or week 32. At week 12, relative liver $(2.8 \pm 0.1)$ and kidney $(0.59 \pm 0.02)$ weights in group 2 rats $(\mathrm{DMH}+\mathrm{DSS} \rightarrow \mathrm{EEP})$ were significantly higher than those in group 1 rats $(p<0.05)$. At week 32 , relative liver weights in group 2 rats $(2.8 \pm 0.1)$ were significantly higher than those in group 1 rats $(2.6 \pm 0.1)$. Similarly, relative liver weights in group 6 rats $(2.8 \pm 0.1)$ were higher than the no-treatment control group 8 rats $(2.7 \pm 0.1)$. Taken together, $1 \%$ EEP may have increased relative liver weights with/without carcinogen treatment. However, these changes in relative weights were less than $10 \%$, which were not regarded as toxic to the animals.

In this study, the propolis intake was calculated from the food intake per rat. Daily intake of EEP and WEP were calculated to be $0.42-0.44 \mathrm{~g} / \mathrm{kg}$ b.w. A previous study showed the median lethal dose $\left(\mathrm{LD}_{50}\right)$ of propolis and its flavonoids in an acute oral toxicity test to be $4-8 \mathrm{~g} / \mathrm{kg}$ in rats, and no adverse effects were seen in rats administered $2.74 \mathrm{~g} / \mathrm{kg}$ b.w./day for 60 days via their drinking water (37). Two-year feeding of $2.5 \%$ EEP, corresponding to $1-2 \mathrm{~g} / \mathrm{kg} / \mathrm{day}$, revealed no carcinogenicity in any organs in male or female rats (38). Therefore, daily intake of $0.42-0.44 \mathrm{~g} / \mathrm{kg}$ of EEP and WEP by rats appears to be well below toxic levels. Consumption of $0.42-0.44 \mathrm{~g} / \mathrm{kg} / \mathrm{day}$ in rats corresponds to a daily intake of approximately $26 \mathrm{~g}$ by a $60 \mathrm{~kg}$ person, but many Japanese companies suggest recommended doses of commercially available propolis ranging from 100 to $500 \mathrm{mg} /$ person/day. However, there are no studies reporting accurate toxicity data of propolis in humans.

Post-initiation treatment with propolis did not alter ACF formation nor tumor yield at week 12. As shown in Table III, post-initiation treatment with $1 \%$ propolis did not significantly alter ACF formation in colonic mucosa (group 1-3). Similarly, there were no differences in tumor incidences at week 12 (Table IV). These results are consistent with previous reports that postinitiation treatment with EEP or WEP did not inhibit colonic ACF formation $(31,32)$, while administration during the initiation period was very effective (30). Taken together, postinitiation treatment with either EEP or WEP does not appear to significantly alter the early steps of colon carcinogenesis in vivo. 

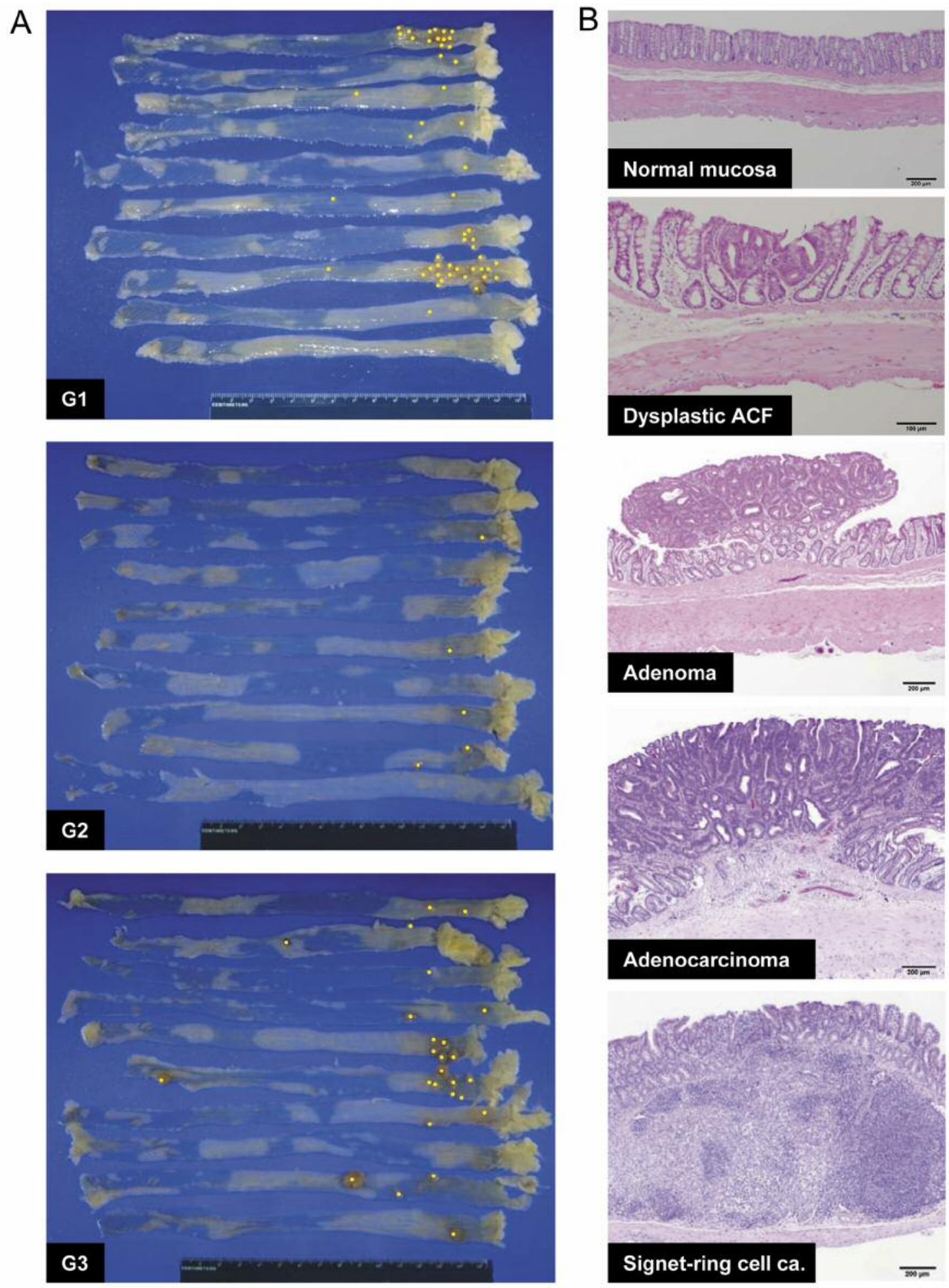

Figure 2. Representative features of the rat colons and tumors at week 32. A: Macroscopic features of the colorectum. Colorectums at week 32 from 10 rats each in groups $(G)$ 1-3 are displayed. Yellow dots indicate each tumor visible on the surface of the extended colorectum. Tumor numbers appear to be reduced in $G 2$ compared with the control G1. Rats of G3 had more large-sized tumors than G1 or G2 rats. B: Microscopic features of colorectal tumors. Chemically induced colorectal tumors are considered to develop sequentially from normal-appearing mucosa to dysplastic aberrant crypt foci $(A C F)$, followed by adenoma and finally adenocarcinoma. Signet-ring cell carcinoma tended to arise from sub-mucosal lymphoid tissues. The histopathology of these neoplastic lesions was well correlated to their sizes. Bars $=200 \mu \mathrm{m}$, except for dysplastic ACF=100 $\mu \mathrm{m}$. 
A

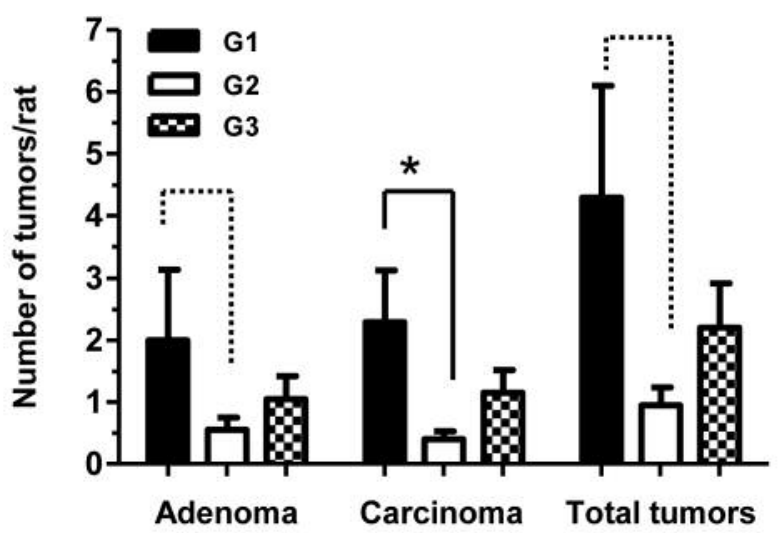

B

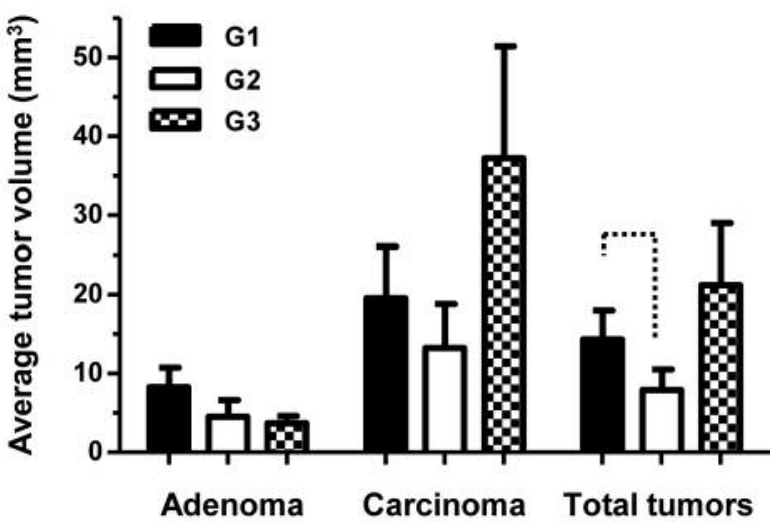

Figure 3. Colorectal tumor multiplicity and volume at week 32. At 32 weeks, all colorectal tumors were histopathologically confirmed. Tumor multiplicity $(A)$ and tumor volume $(B)$ were calculated for adenomas, carcinomas, and total tumors for each treatment group. Data are expressed as the mean \pm SEM. Dashed lines indicate a tendency for difference between the groups 1 and 2, with p-values of 0.2262 (adenoma multiplicity), 0.0861 (total tumor multiplicity) and 0.1598 (total tumor volume). *Statistically significant difference between the groups at $p<0.05$.

Post-initiation treatment with EEP but not WEP significantly reduced colonic tumor yield at week 32. At week 32, a total of 71 tumors were generated in the 17 group- 1 rats, 19 tumors in the 20 group- 2 rats, and 44 tumors in the 20 group- 3 rats. No tumors were found in the the 8 rats of group 4 . Representative appearances of rat colons (10 rats from each group) are shown in Figure 2A, displaying an apparently lower number of tumors in the colons of group 2 rats, as illustrated by the yellow dots. Each tumor was histopathologically diagnosed and representative microscopic findings are shown in Figure 2B. Typically, in chemically induced models, colon tumorigenic processes progressfrom normal mucosa to dysplastic ACF, tubular adenoma, and then adenocarcinoma. In addition, signetring cell carcinoma tends to arise from the region near the submucosal lymphoid tissue. The tumor incidence at weeks 12 and 32 are summarized in Table IV. Although post-initiation treatment with propolis would not be expected to alter the early stages of colon tumorigenesis and did not appear to affect tumor development at week 12 or adenoma incidence at week 32 , the incidence of carcinoma did tend to decrease in group 2 rats (35\%) compared to control group 1 rats $(64.7 \%)$ at week 32.

The most notable findings were the effects of EEP on tumor multiplicity and tumor volume data (Figure 3). The 17 control group 1 rats had 37 carcinomas (adenocarcinoma plus signetring cell carcinoma) and 34 adenomas, the 20 EEP-treated G2 rats had 8 carcinomas and 11 adenomas, and the 20 WEPtreated $\mathrm{G} 3$ rats had 23 carcinomas and 21 adenomas. As shown in Figure $3 \mathrm{~A}$, the average number of carcinomas/rat was significantly lower in group 2 rats compared to group 1 rats ( $p=0.0398$ by Welch's $t$-test). Carcinoma multiplicity in group 3 rats also tended to decrease, but without statistical significance. No statistical significances were obtained in multiplicities of adenoma or total tumor numbers. However, EEP administration apparently affected the colonic mucosa (as described below), possibly reducing the number of adenomas as well as carcinomas. It should be noted that compared to controls, the average tumor volume seemed to be lower ( $p=0.1598$ by Welch's $t$-test) only in the EEP-treated rats (group 2). In contrast, the average carcinoma size was actually increased by WEP treatment compared to the group 1 controls. Thus, WEP failed to suppress tumorigenesis significantly in the post-initiation phase.

Post-initiation treatment with EEP significantly suppressed inflammation and oxidative stress. It is widely accepted that colon carcinogenesis is driven by a series of mutations and alterations of multiple genes. The early steps of colon carcinogenesis can be triggered by $A p c$ gene mutation, followed by nuclear accumulation of $\beta$-catenin protein, which may enhance ACF formation and tumorigenesis (39). In the present study, treatment with EEP did not reduce the nuclear staining of APC nor increase nuclear staining $\beta$-catenin in tumor epithelial cells at week 32 (Table V). Nor did EEP treatment affect ACF formation at week 12 (Table III), cell proliferation at week 32 (PCNA-positive cells; Table V), or apoptosis at week 32 (TUNEL staining; Table V). Notably, while expression of the inflammation-inducible form of cyclooxygenase, $\mathrm{COX} 2$, in colorectal tumors was not affected by EEP or WEP treatment, iNOS expression was significantly down-regulated in the stromal cells of the tumors from EEPtreated rats (Table V). Moreover, protein expression levels for TNF $\alpha, N F-K B$ and GPX2 were significantly diminished in many of the tumors from EEP-treated but not WEP-treated rats (Table VI). Similar patterns were also observed in normal- 
Table V. Immunohistochemical (IHC) evaluation of colorectal tumors at week 32.

\begin{tabular}{|c|c|c|c|}
\hline $\begin{array}{l}\text { Group } \\
\text { Treatment }\end{array}$ & $\begin{array}{c}\mathrm{G} 1 \\
\mathrm{DMH}+\mathrm{DSS} \rightarrow \text { Basal }\end{array}$ & $\begin{array}{c}\mathrm{G} 2 \\
\mathrm{DMH}+\mathrm{DSS} \rightarrow \mathrm{EEP}\end{array}$ & $\begin{array}{c}\mathrm{G} 3 \\
\mathrm{DMH}+\mathrm{DSS} \rightarrow \text { WEP }\end{array}$ \\
\hline \multicolumn{4}{|l|}{ IHC positivity } \\
\hline No. of tumors examined & $\mathrm{n}=15$ & $\mathrm{n}=10$ & $\mathrm{n}=11$ \\
\hline PCNA index ${ }^{a}$ & $55.6 \pm 2.2$ & $54.9 \pm 2.3$ & $50.9 \pm 1.8$ \\
\hline No. of tumors examined & $\mathrm{n}=15$ & $\mathrm{n}=12$ & $\mathrm{n}=13$ \\
\hline TUNEL ${ }^{\mathrm{a}}$ & $0.32 \pm 0.03$ & $0.32 \pm 0.03$ & $0.27 \pm 0.02$ \\
\hline No. of tumors examined & $\mathrm{n}=58$ & $\mathrm{n}=14$ & $\mathrm{n}=37$ \\
\hline $\mathrm{APC}^{\mathrm{b}}$ & $46.6 \%(27 / 58)$ & $35.7 \%(5 / 14)$ & $43.2 \%(16 / 37)$ \\
\hline$\beta$-catenin $\mathrm{b}$ & $62.1 \%(36 / 58)$ & $50.0 \%(7 / 14)$ & $67.6 \%(25 / 37)$ \\
\hline \multicolumn{4}{|l|}{$\mathrm{iNOS}^{\mathrm{c}}$} \\
\hline \multicolumn{4}{|l|}{ Epithelial cells } \\
\hline- & $41.4 \%(24 / 58)$ & $42.9 \%(6 / 14)$ & $29.7 \%(11 / 37)$ \\
\hline \pm & $12.1 \%(7 / 58)$ & $35.7 \%(5 / 14)$ & $16.2 \%(6 / 37)$ \\
\hline+ & $46.6 \%(27 / 58)$ & $21.4 \%(3 / 14)$ & $54.1 \%(20 / 37)$ \\
\hline \multicolumn{4}{|l|}{ Stromal cells } \\
\hline- & $17.2 \%(10 / 58)$ & $42.9 \%(6 / 14)^{*}$ & $16.2 \%(6 / 37)$ \\
\hline \pm & $72.4 \%(42 / 58)$ & $57.1 \%(8 / 14)$ & $75.7 \%(28 / 37)$ \\
\hline+ & $10.3 \%(6 / 58)$ & $0 \%(0 / 14)$ & $8.1 \%(3 / 37)$ \\
\hline \multicolumn{4}{|l|}{$\mathrm{COX} 2^{\mathrm{c}}$} \\
\hline \multicolumn{4}{|l|}{ Epithelial cells } \\
\hline- & $24.1 \%(14 / 58)$ & $28.6 \%(4 / 14)$ & $8.1 \%(3 / 37)$ \\
\hline \pm & $70.7 \%(41 / 58)$ & $71.4 \%(10 / 14)$ & $89.2 \%(33 / 37)$ \\
\hline+ & $5.2 \%(3 / 58)$ & $0 \%(0 / 14)$ & $2.7 \%(1 / 37)$ \\
\hline \multicolumn{4}{|l|}{ Stromal cells } \\
\hline- & $0 \%$ & $0 \%$ & $0 \%$ \\
\hline+ & $12.1 \%(7 / 58)$ & $7.1 \%(1 / 14)$ & $10.8 \%(4 / 37)$ \\
\hline++ & $69.0 \%(40 / 58)$ & $71.4 \%(10 / 14)$ & $73.0 \%(27 / 37)$ \\
\hline+++ & $19.0 \%(11 / 58)$ & $21.4 \%(3 / 14)$ & $16.2 \%(6 / 37)$ \\
\hline
\end{tabular}

DMH: 1,2-Dimethylhydrazine; DSS: dextran sodium sulfate; EEP: ethanol-extracted propolis; WEP: water-extracted propolis. *Significantly different from G1 at $p<0.05$ ( $\chi^{2}$ test). a In epithelium of randomly selected colonic tumors and the data are expressed as mean positivity \pm SEM. ${ }^{b}$ positivity: $\geq 10 \%$ of positively stained nuclei in colonic tumor epithelial cells; ${ }_{-}$, , none; \pm , faintly and partially stained; + , mild-moderately stained in $\leq 50 \%$ cells; ++, mild-moderately stained in $>50 \%$ cells and/or strongly stained in $\leq 50 \%$ cells; +++ , strongly stained in $>50 \%$ cells.

appearing colonic mucosa adjacent to each tumor (data not shown). These findings suggest that suppression of inflammation and oxidative stress by EEP very likely contributed to the reduction of colorectal tumor number and size in EEP-treated rats.

\section{Discussion}

We found that ethanol-extracted Brazilian green propolis exhibited an anti-inflammatory potential when administered in the post-initiation phase of inflammation associated CRC, significantly reducing tumor burden. To our knowledge, this is the first study directly comparing the effects of EEP and WEP treatment on inflammation-associated rat colon tumorigenesis. Our results strongly suggest that there is a positive relationship between the anti-oxidative potential and anti-tumorigenic efficacy of EEP, suggesting that co-administration of EEP, and possibly other naturally occurring anti-oxidative agents, with commercially available non-steroidal anti-inflammatory drugs may synergize to prevent colitis-associated CRC in patients with IBD.

The rat model of colon carcinogenesis used in this study utilized DMH to initiate multi-step carcinogenesis. Although $\mathrm{DMH}$ can cause direct injury to colonic mucosa, it can also be metabolically activated by the cytochrome P450 (CYP) 2E1 enzyme in the liver (40). Propolis has an inhibitory effect of CYP2E1 activity $(41,42)$; therefore, pre-treatment with propolis before carcinogen exposure might reduce CYP2E1 activity, resulting in inhibition of DMH-mediated colon genotoxicity, as reported elsewhere (31). The present study was designed to investigate the effect of propolis on the postinitiation stage of colon carcinogenesis; accordingly, propolis was administered to rats beginning 2 weeks after the final $\mathrm{DMH}$ injection. Consequently, EEP-mediated reduction of tumor burden was not achieved through its effects on CYP2E1 activity. Thus, while tumor burden was reduced at 32 weeks, 
Table VI. Immunohistochemical (IHC) scoring in colorectal tumors at week 32. A total of 71, 19 and 44 (or 41) colorectal tumors were examined by IHC for inflammation- and oxidative stress-related proteins glutathione peroxidase-2 (GPX2), nuclear factor-kappa B (NF-kB) and tumor necrosis factor alpha $(T N F \alpha)$. IHC scoring in the cytoplasm for GPX2,NF-KB and TNF $\alpha$ was performed using the criterion:-, none; \pm , faintly stained in some epithelial areas, or fewer than $5 \%$ of stromal cells were positively stained; + , mildly stained in the cytoplasm of epithelial cells, or $\geq 5$ to $<25 \%$ stromal cells were positive; ++ , moderately stained in the majority of the epithelial cells, or $\geq 25$ to $<50 \%$ stromal cells were positive; +++ , strongly stained in the majority of the epithelial cells or $\geq 50 \%$ stromal cells were positive.

\begin{tabular}{|c|c|c|c|c|}
\hline & $\begin{array}{c}\text { Group } \\
\text { Treatment }\end{array}$ & $\begin{array}{c}\mathrm{G} 1 \\
\mathrm{DMH}+\mathrm{DSS} \rightarrow \text { Basal }\end{array}$ & $\begin{array}{c}\mathrm{G} 2 \\
\mathrm{DMH}+\mathrm{DSS} \rightarrow \mathrm{EEP}\end{array}$ & $\begin{array}{c}\mathrm{G} 3 \\
\mathrm{DMH}+\mathrm{DSS} \rightarrow \mathrm{WEP}\end{array}$ \\
\hline \multicolumn{5}{|l|}{ NF-kB scoring } \\
\hline Tumors examined & & $\mathrm{n}=71$ & $\mathrm{n}=19$ & $\mathrm{n}=44$ \\
\hline \multirow{5}{*}{ Epithelial cells } & - & $0 \%$ & $0 \%$ & $0 \%$ \\
\hline & \pm & $19.7 \%(14 / 71)$ & $42.1 \%(8 / 19)^{*}$ & $31.8 \%(14 / 44)$ \\
\hline & + & $62.0 \%(44 / 71)$ & $52.6 \%(10 / 19)$ & $54.5 \%(24 / 44)$ \\
\hline & ++ & $18.3 \%(13 / 71)$ & $5.3 \%(1 / 19)$ & $13.6 \%(6 / 44)$ \\
\hline & +++ & $0 \%$ & $0 \%$ & $0 \%$ \\
\hline \multirow[t]{5}{*}{ Stromal cells } & - & $0 \%$ & $0 \%$ & $0 \%$ \\
\hline & \pm & $0 \%$ & $0 \%$ & $0 \%$ \\
\hline & + & $19.7 \%(14 / 71)$ & $31.6 \%(6 / 19)$ & $4.5 \%(2 / 44) * *$ \\
\hline & ++ & $56.3 \%(40 / 71)$ & $63.2 \%(12 / 19)$ & $52.3 \%(23 / 44)$ \\
\hline & +++ & $23.9 \%(17 / 71)$ & $5.3 \%(1 / 19)$ & $43.2 \%(19 / 44)^{* *}$ \\
\hline \multicolumn{5}{|l|}{ TNF $\alpha$ scoring } \\
\hline Tumors examined & $\mathrm{n}=71$ & $\mathrm{n}=19$ & $n=41$ & \\
\hline \multirow[t]{5}{*}{ Epithelial cells } & - & $0 \%$ & $31.6 \%(6 / 19)^{*}$ & $0 \%(\mathrm{~d})$ \\
\hline & \pm & $56.3 \%(40 / 71)$ & $36.8 \%(7 / 19)$ & $19.5 \%(8 / 41)^{*}$ \\
\hline & + & $43.7 \%(31 / 71)$ & $26.3 \%(5 / 19)$ & $56.1 \%(23 / 41)$ \\
\hline & ++ & $0 \%$ & $5.3 \%(1 / 19)$ & $22.0 \%(9 / 41)^{*}$ \\
\hline & +++ & $0 \%$ & $0 \%$ & $2.4 \%(1 / 41)$ \\
\hline \multirow[t]{5}{*}{ Stromal cells } & - & $5.6 \%(4 / 71)$ & $47.4 \%(9 / 19)^{*}$ & $2.4 \%(1 / 41)^{* *}$ \\
\hline & \pm & $31.0 \%(22 / 71)$ & $21.1 \%(4 / 19)$ & $9.8 \%(4 / 41)^{*}$ \\
\hline & + & $50.7 \%(36 / 71)$ & $21.1 \%(4 / 19)^{*}$ & $41.5 \%(17 / 41)$ \\
\hline & ++ & $12.7 \%(9 / 71)$ & $10.5 \%(2 / 19)$ & $39.0 \%(16 / 41)^{* *}$ \\
\hline & +++ & $0 \%$ & $0 \%$ & $7.3 \%(3 / 41)$ \\
\hline \multicolumn{5}{|l|}{ GPX2 scoring } \\
\hline Tumors examined & $\mathrm{n}=71$ & $\mathrm{n}=19$ & $\mathrm{n}=41$ & \\
\hline \multirow[t]{5}{*}{ Epithelial cells } & - & $0 \%$ & $0 \%$ & $0 \%$ \\
\hline & \pm & $5.6 \%(4 / 71)$ & $15.8 \%(3 / 19)$ & $0 \%$ \\
\hline & + & $15.5 \%(11 / 71)$ & $21.1 \%(4 / 19)$ & $34.1 \%(14 / 41)$ \\
\hline & ++ & $76.1 \%(54 / 71)$ & $63.2 \%(12 / 19)$ & $63.4 \%(26 / 41)$ \\
\hline & +++ & $2.8 \%(2 / 71)$ & $0 \%$ & $2.4 \%(1 / 41)$ \\
\hline \multirow[t]{5}{*}{ Stromal cells } & - & $0 \%$ & $0 \%$ & $0 \%$ \\
\hline & \pm & $4.2 \%(3 / 71)$ & $26.3 \%(5 / 19)^{*}$ & $0 \%$ \\
\hline & + & $18.3 \%(13 / 71)$ & $21.1 \%(4 / 19)$ & $12.2 \%(5 / 41)$ \\
\hline & ++ & $50.7 \%(36 / 71)$ & $52.6 \%(10 / 19)$ & $78.0 \%(32 / 41)$ \\
\hline & +++ & $26.8 \%(19 / 71)$ & $0 \% *$ & $9.8 \%(4 / 41)$ \\
\hline
\end{tabular}

Significantly different at $p<0.05$ from *group 1 (Fisher's exact probability or $\chi^{2}$ test), and **group 2 (Fisher's exact probability test).

post-initiation treatment was insufficient to inhibit formation of ACF or tumors at week 12.

Inflammatory cells such as neutrophils and macrophages are able to generate reactive oxygen and nitrogen species, such as $\mathrm{O}_{2}^{-}$radicals, $\mathrm{H}_{2} \mathrm{O}_{2}, \mathrm{HOCl}$, and nitric oxide, which can induce DNA damage, DNA mutations and chromosomal aberrations. Activated neutrophils and macrophages also express inflammatory cytokines including $\mathrm{TNF} \alpha$, which can activate $\mathrm{NF}-\mathrm{KB}$ signaling that plays a central role in multiple human diseases $(4,43)$. Inflammation-activated NF-кB leads to transcriptional up-regulation of downstream molecules, including anti-oxidative GPX2, a selenium-dependent glutathione peroxidase which exerts hydrogen peroxidereducing activity in gastrointestinal mucosa (44), and iNOS. Therefore, chronic inflammation can result in expression of GPX2 and iNOS as well as TNF $\alpha$ and NF-kB. However, it has been reported that artepillin $\mathrm{C}$, a major active component of Brazilian green propolis, can strongly suppress the activity of inflammation-related macrophages, resulting in significant suppression of $\mathrm{NF}-\mathrm{kB}$ (p65) and $\mathrm{TNF} \alpha$ in vitro (25). Our data 
clearly show suppression of TNF $\alpha, \mathrm{NF}-\mathrm{kB}$, GPX2, and iNOS in tumors that developed in rats administered EEP, but not WEP.

The molecular mechanisms of action by propolis and its components involve a wide spectrum of biological functions, and induction of apoptosis has been considered to be a significant mode of action (28-30); however, induction of apoptosis in EEP-administered rats was not observed in this study. Nevertheless, it is highly likely that EEP contains proapoptotic component(s). For example, Kumazaki et al. reported that the major constituents of propolis such as artepilin $\mathrm{C}$, baccharin and drupanin induced both intrinsic and extrinsic apoptosis in human colon cancer cells through the upregulation of $m i R-143$ and suppression of the target genes, such as mitogen-activated protein kinase/extracellular signalregulated kinase 5 and $c-M Y C$ (45). Therefore, our observation that post-initiation-administered EEP lacked apoptosis-inducing activity requires additional confirmation. In addition, it has been reported that propolis and its components may possess immunomodulatory functions that can activate innate antitumor immune surveillance and responses (14). This possibly also warrants further investigation.

Our data strongly suggest that malignant progression from adenoma to carcinoma was effectively suppressed by EEP. Recently, Kakehashi et al. demonstrated that 2-year administration of $2.5 \%$ EEP in the diet exerted anticarcinogenic potential and significantly reduced the incidence of several naturally occurring tumors in male and female rats (38). These results taken together with the results of the present study suggest that propolis could be developed as a supportive product targeting patients with IBD, including patients with ulcerative colitis and Crohn's disease, who may continuously need anti-inflammatory drugs.

In conclusion, EEP reduced tumor burden in DMH/DSStreated rats by suppressing malignant progression from adenoma to carcinoma. Suppression of inflammation and oxidative stress is one demonstrable mechanism of action by which post-initiation phase administration of EEP led to this anti-carcinogenic response. However, additional studies are warranted to further clarify the mechanisms by which Brazilian green propolis exerts in vivo.

\section{Acknowledgements}

The Authors thank Rie Onodera, Keiko Sakata and Yuko Hisabayashi for their technical assistance. This study was supported in part by a grant from the Ministry of Education, Culture, Sports, Science and Technology of Japan.

\section{References}

1 Siegel RL, Miller KD and Jemal A: Cancer statistics, 2016. CA Cancer J Clin 66: 7-30, 2016.

2 Watanabe T, Itabashi M, Shimada Y, Tanaka S, Ito Y, Ajioka Y, Hamaguchi T, Hyodo I, Igarashi M, Ishida H, Ishihara S, Ishiguro
M, Kanemitsu Y, Kokudo N, Muro K, Ochiai A, Oguchi M, Ohkura Y, Saito Y, Sakai Y, Ueno H, Yoshino T, Boku N, Fujimori T, Koinuma N, Morita T, Nishimura G, Sakata Y, Takahashi K, Tsuruta O, Yamaguchi T, Yoshida M, Yamaguchi N, Kotake K and Sugihara K: Japanese Society for Cancer of the Colon and Rectum. Japanese Society for Cancer of the Colon and Rectum (JSCCR) Guidelines 2014 for treatment of colorectal cancer. Int J Clin Oncol 20: 207-239, 2015.

3 Raskov H, Pommergaard HC, Burcharth $\mathrm{J}$ and Rosenberg J: Colorectal carcinogenesis-update and perspectives. World J Gastroenterol 20: 18151-18164, 2014.

4 Klaunig JE, Kamendulis LM and Hocevar BA: Oxidative stress and oxidative damage in carcinogenesis. Toxicol Pathol 38: 96$109,2010$.

5 Ullman TA and Itzkowitz SH: Intestinal inflammation and cancer. Gastroenterology 140: 1807-1816, 2011.

6 Guina T, Biasi F, Calfapietra S, Nano $M$ and Poli G: Inflammatory and redox reactions in colorectal carcinogenesis. Ann NY Acad Sci 1340: 95-103, 2015.

7 Chan AT, Ogino S and Fuchs CS: Aspirin and the risk of colorectal cancer in relation to the expression of COX2. N Engl J Med 356: 2131-2142, 2007.

$8 \mathrm{Ng} \mathrm{K}$, Meyerhardt JA, Chan AT, Sato K, Chan JA, Niedzwiecki D, Saltz LB, Mayer RJ, Benson AB 3rd, Schaefer PL, Whittom R, Hantel A, Goldberg RM, Venook AP, Ogino S, Giovannucci EL and Fuchs CS: Aspirin and COX2 inhibitor use in patients with stage III colon cancer. J Natl Cancer Inst 107: dju345, 2015.

9 Cohen SM and Arnold LL: Chemical carcinogenesis. Toxicol Sci 120: S76-S92, 2011.

10 Toyoda-Hokaiwado N, Yasui Y, Muramatsu M, Masumura K, Takamune M, Yamada M, Ohta T, Tanaka T and Nohmi T: Chemopreventive effects of silymarin against 1,2dimethylhydrazine plus dextran sodium sulfate-induced inflammation-associated carcinogenicity and genotoxicity in the colon of gpt delta rats. Carcinogenesis 32: 1512-1517, 2011.

11 Arigesavan K and Sudhandiran G: Carvacrol exhibits antioxidant and anti-inflammatory effects against 1, 2-dimethyl hydrazine plus dextran sodium sulfate induced inflammation associated carcinogenicity in the colon of Fischer 344 rats. Biochem Biophys Res Commun 461: 314-320, 2015.

12 Kim SL, Liu YC, Seo SY, Kim SH, Kim IH, Lee SO, Lee ST, Kim DG and Kim SW: Parthenolide induces apoptosis in colitisassociated colon cancer, inhibiting NF-kB signaling. Oncol Lett 9: 2135-2142, 2015.

13 Burdock GA: Review of the biological properties and toxicity of bee propolis (Propolis). Food Chem Toxicol 36: 347-363, 1998.

14 Sforcin JM: Propolis and immune system: a review. J Ethnopharmacology 113: 1-14, 2007.

15 Choudhari MK, Haghniaz R, Rajwade JM and Paknikar KM: Anticancer activity of Indian stingless bee propolis: an in vitro study. Evid Based Complement Alternat Med 2013: 928280, 2013.

16 Teerasripreecha D, Phuwapraisirisan P, Puthong S, Kimura K, Okuyama $\mathrm{M}$, Mori $\mathrm{H}$, Kimura $\mathrm{A}$ and Chanchao $\mathrm{C}$ : In vitro antiproliferative/cytotoxic activity on cancer cell lines of a cardanol and a cardol enriched from Thai Apis mellifera propolis. BMC Complement Altern Med 12: 27, 2012.

17 Kubina R, Kabała-Dzik A, Dziedzic A, Bielec B, Wojtyczka RD, Bułdak RJ, Wyszyńska M, Stawiarska-Pięta B and SzaflarskaStojko E: The ethanol extract of polish propolis exhibits antiproliferative and/or pro-apoptotic effect on HCT 116 colon cancer 
and Me45 malignant melanoma cells in vitro conditions. Adv Clin Exp Med 24: 203-212, 2015.

18 Zhang J, Cao X, Ping S, Wang K, Shi J, Zhang C, Zheng H and $\mathrm{Hu}$ F: Comparisons of ethanol extracts of chinese propolis (poplar type) and poplar gums based on the antioxidant activities and molecular mechanism. Evid Based Complement Alternat Med 2015: 307594, 2015.

19 Bankova V, Popova M and Trusheva B: Propolis volatile compounds: chemical diversity and biological activity: a review. Chem Cent J 8: 28, 2014.

20 Machado BA, Barreto Gde A, Costa AS, Costa SS, Silva RP, da Silva DF, Brandão HN, da Rocha JL, Nunes SB, Umsza-Guez MA and Padilha FF: Determination of parameters for the supercritical extraction of antioxidant compounds from green propolis using carbon dioxide and ethanol as co-solvent. PLoS One 10: e0134489, 2015.

21 Machado BA, Silva RP, Barreto Gde A, Costa SS, Silva DF, Brandão HN, Rocha JL, Dellagostin OA, Henriques JA, UmszaGuez MA and Padilha FF: Chemical composition and biological activity of extracts obtained by supercritical extraction and ethanolic extraction of brown, green and red propolis derived from different geographic regions in Brazil. PLoS One 11: e0145954, 2016.

22 Nakajima Y, Tsuruma K, Shimazawa M, Mishima S and Hara H: Comparison of bee products based on assays of antioxidant capacities. BMC Complement Altern Med 9: 4, 2009.

23 Machado JL, Assunção AK, da Silva MC, Dos Reis AS, Costa GC, Arruda Dde S, Rocha BA, Vaz MM, Paes AM, Guerra RN, Berretta AA and do Nascimento FR: Brazilian green propolis: anti-inflammatory property by an immunomodulatory activity. Evid Based Complement Alternat Med 2012: 157652, 2012.

24 Shimizu K, Ashida H, Matsuura $\mathrm{Y}$ and Kanazawa $\mathrm{K}$ : Antioxidative bioavailability of artepillin $\mathrm{C}$ in Brazilian propolis Arch Biochem Biophys 424: 181-188, 2004.

25 Szliszka E, Mertas A, Czuba ZP and Król W: Inhibition of inflammatory response by artepillin C in activated RAW264.7 macrophages. Evid Based Complement Alternat Med 2013: 735176, 2013.

26 Xie XL, Gi M, Fujioka M, Doi K, Yamano S, Tachibana H, Fang $\mathrm{H}$, Kakehashi A and Wanibuchi $\mathrm{H}$ : Ethanol-extracted propolis enhances BBN-initiated urinary bladder carcinogenesis via nonmutagenic mechanisms in rats. Food Chem Toxicol 83: 193-200, 2015.

27 Song YS, Jin C, Jung KJ and Park EH: Estrogenic effects of ethanol and ether extracts of propolis. J Ethnopharmacol 82: 89-95, 2002.

28 Watanabe MA, Amarante MK, Conti BJ and Sforcin JM: Cytotoxic constituents of propolis inducing anticancer effects: a review. J Pharm Pharmacol 63: 1378-1386, 2011.

29 Akao Y, Maruyama H, Matsumoto K, Ohguchi K, Nishizawa K, Sakamoto T, Araki Y, Mishima S and Nozawa Y: Cell growth inhibitory effect of cinnamic acid derivatives from propolis on human tumor cell lines. Biol Pharm Bull 26: 1057-1059, 2003.

30 Yasui Y, Miyamoto S, Kim M, Kohno H, Sugie S and Tanaka T: Aqueous and ethanolic extract fractions from the Brazilian propolis suppress azoxymethane-induced aberrant crypt foci in rats. Oncol Rep 20: 493-499, 2008.

31 de Lima RO, Bazo AP, Said RA, Sforcin JM, Bankova V, Darros BR and Salvadori DM: Modifying effect of propolis on dimethylhydrazine-induced DNA damage but not colonic aberrant crypt foci in rats. Environ Mol Mutagen 45: 8-16, 2005.
32 Kawabe M, Lin C, Kimoto N, Sano M, Hirose M and Shirai T: Modifying effects of propolis on MeIQx promotion of rat hepatocarcinogenesis and in a female rat two-stage carcinogenesis model after multiple carcinogen initiation. Nutr Cancer 37: 179-186, 2000.

33 Doi K, Wanibuchi H, Salim EI, Morimura K, Kinoshita A, Kudoh S, Hirata K, Yoshikawa J and Fukushima S: Lack of large intestinal carcinogenicity of 2-amino-1-methyl-6-phenylimidazo [4,5-b]pyridine at low doses in rats initiated with azoxymethane. Int J Cancer 115: 870-878, 2005.

34 Tomayko MM and Reynolds CP: Determination of subcutaneous tumor size in athymic (nude) mice. Cancer Chemother Pharmacol 24: 148-154, 1989.

35 Takemiya M, Miyayama H and Takeuchi T: Pathogenesis of 1,2dimethylhydrazine-induced carcinomas in rat intestine. I. The induction of mucin producing carcinomas in rat intestine. Acta Pathol Jpn 32: 257-264, 1982.

36 Bird RP: Observation and quantification of aberrant crypts in the murine colon treated with a colon carcinogen: preliminary findings. Cancer Lett 37: 147-151, 1987.

37 Almeida EC and Menezes H: Anti-inflammatory activity of propolis extracts: a review. J Venom Anim Toxins 8: 191-212, 2002.

38 Kakehashi A, Ishii N, Fujioka M, Doi K, Gi M and Wanibuchi $\mathrm{H}$ : Ethanol-extracted Brazilian propolis exerts protective effects on tumorigenesis in Wistar Hannover rats. PLoS One 11: e0158654, 2016.

39 Alrawi SJ, Schiff M, Carroll RE, Dayton M, Gibbs JF, Kulavlat M, Tan D, Berman K, Stoler DL and Anderson GR: Aberrant crypt foci. Anticancer Res 26: 107-119, 2006.

40 Hayashi N, Tsutsumi M, Fukura M, Yano H, Tsuchishima M and Takase S: Effect of chronic dietary ethanol consumption on colonic cancer in rats induced by 1,1-dimethylhydrazine. Alcohol Clin Exp Res 31: S72-76, 2007.

41 Ryu CS, Oh SJ, Oh JM, Lee JY, Lee SY, Chae JW, Kwon KI and Kim SK: Inhibition of cytochrome P450 by propolis in human liver microsomes. Toxicol Res 32: 207-213, 2016.

42 Naramoto K, Kato $M$ and Ichihara K: Effects of an ethanol extract of Brazilian green propolis on human cytochrome $\mathrm{P} 450$ enzyme activities in vitro. J Agric Food Chem 62: 11296-11302, 2014.

43 Reuter S, Gupta SC, Chaturvedi MM and Aggarwal BB: Oxidative stress, inflammation, and cancer: How are they linked? Free Radic Biol Med 49: 1603-1616, 2010.

44 Müller MF, Florian S, Pommer S, Osterhoff M, Esworthy RS, Chu FF, Brigelius-Flohé R and Kipp AP: Deletion of glutathione peroxidase-2 inhibits azoxymethane-induced colon cancer development. PLoS One 8: e72055, 2013.

45 Kumazaki M, Shinohara H, Taniguchi K, Yamada N, Ohta S, Ichihara $\mathrm{K}$ and Akao Y: Propolis cinnamic acid derivatives induce apoptosis through both extrinsic and intrinsic apoptosis signaling pathways and modulate of miRNA expression. Phytomedicine 21: 1070-1077, 2014. 